\begin{abstract}
Although parents are essential to child sexual abuse (CSA) prevention efforts, their views on prevention and protection are not always represented in the research literature. In this qualitative study of 24 Australian parents, beliefs about CSA, its risk factors, prevention methods, and parents' role in CSA protection, and parents' approaches to protection of their own children, are examined. Findings were condensed into five themes: (a) parents' understanding of child sexual abuse, grooming and risk; (b) parent-led CSA education; (c) parents' beliefs about CSA education; (d) children recognizing and resisting CSA; and (e) parent responsibility for protection. Findings suggest that parents have a good knowledge of CSA and its risks. However, they do not provide their children with the comprehensive prevention messages recommended by prevention campaigns and many concentrate on abduction dangers. This gap between knowledge and parental communication with children could be due to parents' beliefs that there may be harms associated with education of children about CSA (e.g., such as inciting new fears and worries or reducing trust in others) and that the method may not be effective in protecting children from CSA. This study adds to the existing literature by presenting information that could be useful in designing programs to include parents in CSA protection and by approaching CSA research with parents as the key agents in the protection of children.
\end{abstract}


Parents and CSA Prevention 2

\section{Parents as Protectors: A Qualitative Study of Parents' Views on \\ Child Sexual Abuse Prevention}

Enhancing parents' protective behaviors has been recommended as a crucial element in comprehensive approaches to the prevention of child sexual abuse (CSA) (Mendelson \& Letourneau, 2015; Rudolph, Zimmer-Gembeck, Shanley, \& Hawkins, 2017; Wurtele, 2010). Yet, there has been little research on parents' views on CSA prevention and the actions they believe they can, or should, take to protect their children (Mendelson \& Letourneau, 2015; Xie, Qiao \& Wang, 2016). Gathering such views from parents could aid the design of attractive and useful prevention initiatives, as interventions have often experienced difficulty engaging parents (Wurtele, 2010). In the present study, Australian parents were interviewed in 2017 with the aim of capturing their understanding, in their own words, of CSA and its prevention. Parents were interviewed about CSA risk factors, the available prevention methods, parents' role in CSA protection, and their approaches to prevention with their own children.

\section{Parental Conceptualization of CSA, Risk and Risk Factors}

The limited research available on parent conceptualization of CSA has primarily relied on surveys. Data suggest that parents have a relatively good understanding of the issues involved in CSA; however, but that they may have a number of misconceptions. Studies since the early 1980s have found parents are aware that CSA is not rare or unusual (Finkelhor, 1984), that abuse is likely to be perpetrated by a family member or known person (Finkelhor, 1984; Hébert, Lavoie \& Parent, 2002; Reppucci, Jones \& Cook, 1994; Tutty, 1993; Xie et al., 2016), that children should be believed (Tutty, 1993), that boys are also at risk (Chen \& Chen, 2005; Elrod \& Rubin, 1993; Finkelhor, 1984), and that physical signs of CSA are not always present (Hébert et al., 2002; Reppucci et al., 1994; Xie et al., 2016). Despite this knowledge, parents' actions and 
beliefs can sometimes be misguided. For example, parents report focusing on strangers in their warnings of abuse (Chen \& Chen, 2005; Chen et al., 2007; Deblinger, Thakkar-Kolar, Berry, \& Schroeder, 2010; Wurtele, Kvaternick \& Franklin, 1992), tell their child to physically retaliate (Wurtele et al., 1992), and underestimate the possibility of young (preschool-aged) victims (Reppucci et al., 1994).

There is a lack of research on parental knowledge about the complex dynamics of sexual abuse, such as whether parents are aware that children may be acquiescent in the abuse, whether peer sexual interaction is abuse and what is involved in perpetrator grooming behaviors. An exception is a recent qualitative study from China which detailed parents' definition of CSA. In this study parents felt sexual contact between an adult and a child under the age of 14 was abusive, even if the child had consented to involvement, however, some parents were not sure if sexual activity with an adult after the age of 14 constituted abuse. Generally, parents thought that some inequality or imbalance must be present for abuse to occur, and that children of the same age and maturity "are just playing games" (Xie et al., 2016, p.1003). Overall, despite these previous studies, there remains a lack of research that provides accounts of parents' personal views and knowledge about the complex dynamics of sexual abuse, including how to defined CSA (e.g., whether or not peer sexual interaction is abuse) and what is involved in perpetrator grooming behaviors (e.g., how children may appear to acquiesce to sexual behavior).

Parents' understanding of CSA risk may affect their implementation of protective behaviors, as outlined in models such as Protective Motivation Theory ${ }^{1}$ (Rogers, 1983). Yet,

\footnotetext{
${ }^{1}$ According to PMT when confronted with a health threat, the individual undertakes cognitive appraisal processes involving: 1) the harmfulness of the threat (severity), 2) the likelihood of occurrence of the event (vulnerability), 3) the efficacy of a recommended coping action in averting the threat (response efficacy), and 4) the individual's belief that they are capable of successfully performing the functional response (self-efficacy). Also impacting on the model are perceived rewards, which increase the likelihood of engaging in the adaptive response, and response-costs which decrease the likelihood that the appropriate response will be undertaken (such as inconvenience, expense,
} 
only three studies were located that addressed parents' descriptions of risk factors. Parents from Botswana and Swaziland identified parental (e.g., negligence), child (e.g., influenced by Western values, sexual disorders) and society (e.g., witchcraft, poverty) risk factors (Mathoma, MaripePerera, Khumalo, Mbayi, \& Seloilwe, 2006). In a study of North American parents, risk factors identified included parental (e.g., alcohol/drug use, lack of supervision, involvement and communication, marital problems, poor parent-child relationship) and child (e.g., gender, age and personality) influences (Collins, 1996). In recent research conducted in China, parents identified physical (sex) and socio-economic factors (poverty, "left-behind" and migrant children resulting from labor migration) as placing children at greater risk of CSA (Xie et al., 2016).

Parents seem to vary widely in their estimation of the proportion of children who will experience CSA, with estimates ranging from 1-to-90\% for girls and 1-to-60\% for boys (Collins, 1996; Finkelhor, 1984; Tutty, 1993). However, parents tend to believe that their own children are at less risk than other children; assessing them to be at low, or no, risk of sexual abuse (Collins, 1996; Elrod \& Rubin, 1993; Finkelhor, 1984; Reppucci et al., 1994; Rudolph, Zimmer-Gembeck, Shanley, Walsh, \& Hawkins, 2018; Tutty, 1993; Xie et al., 2016). An aim of the present study was to capture parents' conceptualization, in their own words, of CSA and grooming, their understanding of its risks and their appraisal of their own children's risk.

\section{Child Education as a Parental Protective Strategy}

Child education is a common CSA prevention tool, with the aim of teaching children to identify, resist and disclose abuse. The home has been described as a suitable place for children to be educated about CSA and parents indicate that they prefer to be their children's primary

unpleasantness, difficulty, complexity, side effects, disruption and overcoming habit strength). The outcomes of these appraisals produce protection motivation, and the enactment of the adaptive, coping response. (Rogers, 1984). 
CSA educators (Elrod \& Rubin, 1993; Foster, 2017; Walsh \& Brandon, 2012; Wurtele et al., 1992). In fact, researchers have used parental discussion of CSA with their children as a way of measuring the extent to which parents are protective (Briggs, 1988; Deblinger et al. 2010; Walsh, Brandon, \& Chirio, 2012; Wurtele et al., 1992; Xie et al., 2016). Recommendations to parents include encouragement to speak with children often and from an early age, about specific abusive behaviors, potential perpetrator identities, and protective strategies (e.g. Darkness to Light, n.d.; Stop it Now, n.d.) Research evaluating school-based CSA education has demonstrated that children make knowledge gains and may be able to better identify inappropriate touch scenarios and appropriate behavioural responses after such a program (Walsh, Zwi, Woolfenden, \& Shlonsky 2018). However, research has yet to demonstrate a link between increased child knowledge (from education programs or through discussion with parents) and reduced CSA incidence (Finkelhor et al., 1995; Finkelhor et al., 2014; Ko \& Cosden, 2001; Pelcovitz et al., 1992).

Parents continue to report that they find it difficult to converse about CSA risks with their children (Deblinger et al., 2010; Rudolph et al., 2018b; Walsh et al., 2012). Parents describe the topic of CSA as more difficult to talk about than intercourse, homosexuality, abortion, suicide and death (Finkelhor, 1984; Rudolph et al., 2018b). In recent studies, $41 \%$ to $98 \%$ of parents have described conversing about CSA risk with their children. For example, Deblinger et al. (2010) reported that $64 \%$ of U.S. parents had told their child that someone might try to touch the child's genitals, mostly warning their children that the perpetrators could be strangers (73\%), and to a lesser degree known adults (50\%), relatives (34\%), parents (21\%) and siblings (19\%). Almost all parents in a study from Nigeria reported telling their child to say no (98\%), and tell a trustworthy adult (96\%), if someone wants to see or touch their private parts, not to accept gifts 
Parents and CSA Prevention 6

from strangers (96\%) and not go anywhere with others without parental permission (97\%) (Ige \& Fawoke, 2011). Walsh et al. (2012) found that although two-thirds of the Australian mothers in their sample reported that they had discussed CSA with their children, they mostly addressed topics related to body integrity (i.e. personal autonomy and self-determination regarding access to one's body), with only $41 \%$ of the total sample of mothers educating their children about when it is ok and not ok for someone to touch their private parts, and $27 \%$ warning their child that perpetrators could be someone the child knows or likes. In the most recent study we could locate, $56 \%$ of Australian and UK parents reported that they had discussed sexual abuse with their children, with $11 \%$ reportedly feeling uncomfortable and $45 \%$ reportedly feeling comfortable doing so (Rudolph et al., 2018b). Comparisons of these statistics is difficult due to the varying definitions of CSA adopted by researchers and the possibility that parents interpreted the term in a variety of ways (Miana \&Collin-Vézina, 2017). Reported discussions of "sexual abuse" could entail talking about stranger danger, abduction, body integrity, private parts or accurate descriptions of abuse, in any amount of detail (Rudolph et al., 2018a).

Studies have documented a variety of reasons for parents' lack of discussion with their children about CSA, including that their children were too young (Briggs, 1988; Deblinger et al., 2010; Finkelhor, 1984; Wurtele et al., 1992; Xie et al., 2015), it might frighten them (Briggs, 1988; Finkelhor, 1984), the topic was too difficult, they were ashamed to discuss it or they did not have the right materials/knowledge (Briggs, 1988; Deblinger et al., 2010; Finkelhor, 1984; Wurtele et al., 1992; Xie et al., 2015), because their children were not at risk of abuse (Briggs, 1988; Finkelhor, 1984, Xie et al., 2015) or it had not occurred to them to discuss the topic with their children (Deblinger et al., 2010; Finkelhor, 1984; Wurtele et al., 1992).

Three qualitative studies on parents and prevention, conducted in the last 10 years, could 
be located in English language publications (Babatsikos \& Miles, 2015; Walsh \& Brandon, 2012; Xie, Qiao \& Wang, 2015). Walsh and colleagues (2012) held 8 focus groups with 30 Australian parents and found that parents reported teaching their children about body awareness, body integrity, private parts, types of touches and assertiveness. Babatsikos and Miles (2015) interviewed 28 Australian parents who reported they strove to balance educating their children about sexual abuse with not frightening or disillusioning them. Possibly due to this delicate balancing act, parents reported mostly discussing stranger danger rather than the danger posed by known adults. They also mentioned telling their children not to keep secrets and about safe and unsafe touches. Although all 26 Chinese parents interviewed by Xie et al. (2015) believed it was necessary to teach children about CSA, only 35\% reported having conversations about CSA risks with their children.

\section{Parental Protective Strategies Other Than Child Education}

Parental engagement of protective behaviors, other than direct education or communication with children about CSA, has been addressed in four qualitative studies. In the first study (Collins, 1996), U.S. parents reported using a range of approaches to protect their children from CSA. Parents felt that an inadequate parent-child relationship and a lack of supervision increased children's vulnerability. To mitigate these risks, parents reported watching their children closely and described their attempts to establish strong relationships with their children, in the hope that this would allow their child to feel comfortable confiding in them, to prevent them being influenced by others, and to build their child's self-esteem. Parents also reported endeavoring to protect their children by taking an interest in their children's lives, including regular questioning about the child's day, interests, concerns and feelings, limiting their children's activities (especially overnight stays) providing CSA education, carefully 
considering child care options and monitoring for signs of abuse.

In another study (Babatsikos, 2011; Babatsikos \& Miles, 2015), Australian parents emphasized good communication with their children. Parents described how open communication was important in building loving and supportive relationships, establishing trust, assisting with the monitoring of situations and addressing of problems, aiding in the detection of problematic scenarios, allowing the identification of solutions, in boundary-setting, and in the general protection of their children. Parents also reported reducing risk by monitoring social situations (such as sporting groups, play dates, and sleepovers), being aware of their child's comfort levels in interpersonal scenarios and being cautious of adults (especially males) who children resisted spending time with or who are unduly affectionate.

Focus groups were used to canvass another sample of Australian parents (Walsh \& Brandon, 2012). Participants recognized that in addition to child education, protecting their children from abuse involved exercising caution, and taking responsibility for supervising and monitoring their children. This vigilance was balanced with a pragmatism that abuse happens, and parents can only do what is "humanly possible to prevent" it (Walsh \& Brandon, 2012, p. 739). A Chinese study, using a majority male sample, focused on parents' roles as CSA educators. Although parenting practices were not addressed specifically, some participants described utilizing general strategies to protect their children such as sending their children to good schools, allowing their children contact with people they trusted, picking them up from school, and not allowing them outside alone, particularly at night (Xie et al., 2015).

These studies suggest that parents are cognizant of the dangers of sexual abuse, consider how these risks apply to their own children, and employ a range of protective strategies to keep their children safe from CSA. The current research builds on these studies, augmenting our 
understanding of how parents view and enact their role as CSA protectors.

\section{The Current Study}

Although a body of quantitative literature on rates of parent-to-child CSA education now exists, there is a notable lack in detailed descriptions of parents' views of prevention and their role within it. Discerning the content of parents' conversations with their children, whether they believe child knowledge is an effective prevention strategy, and how they feel about any unintended side-effects, can inform CSA prevention endeavours. This information gap, filled by the current study, may help to identify why parents do not discuss CSA with their children or why they provide ambiguous and/or limited messages. Variables examined in this study may help guide the future development, evaluation and implementation of programs to help parents participate fully in the prevention of CSA.

Using a qualitative research design, the aim of the current study was to capture parents' beliefs about CSA, its risks and prevention, and their roles as protectors. The research was approached with the view that parents are the most proximal figures in their children's social ecology, and therefore are crucial protagonists in CSA protection.

\section{Method}

\section{Participants}

Participants were 17 mothers and seven fathers, aged 30-to-59, living in a suburban, coastal city in Australia. Three parents spoke a language other than English at home, and 13 were born outside Australia. Eighteen participants identified as white/Caucasian, three as Asian and one each as Hispanic, Australian Aboriginal, and Middle Eastern. All participants were the biological parents of between 1-to-4 children, ranging in age from newborn to 16 years. Nineteen participants were married or co-habitating with a partner, and five were separated. Participants 
ranged in education from ninth grade to doctoral level. More than half of the sample $(62.5 \%)$ had annual incomes above $\$ 100000$. When asked to report income range, $16.7 \%(n=4)$ reported income under $\$ 50,000,20.8 \%(n=5)$ reported $\$ 50,000$ to $\$ 100,000,41.7 \%(n=10)$ reported $\$ 100,000$ to $\$ 150,000$, and $20.8 \%(n=5)$ reported over $\$ 150,000$ annually.

\section{Recruitment and Consent}

The research study was approved by a university Human Subjects Review Committee. Participants were recruited through flyers at a primary school, and at a child-focused psychology clinic located in a university. The flyer called for parents with children under 18 to volunteer in discussions around parenting, keeping children safe, and sexual abuse. Participants registered their interest by contacting the lead researcher by phone or email. Prior to interview, respondents were informed that their participation was voluntary, that they could withdraw at any time, that their data would be kept confidential and of the limits of confidentiality. They were also given the contact details for several sexual abuse community organizations to contact for support, if needed. After the study was described, all participants signed a written consent to participate. Interviews took place either at the school, university, participant's home or community location such as a cafe or library. The first author conducted all the interviews.

\section{Measures}

Interview. An audio-recorded interview of approximately one hour was conducted by the first author. Participants completed a form providing their demographic information, including age, income, education and child details at end of the interview. Participants were compensated for their participation with a gift voucher valued between $\$ 20$ and $\$ 50$.

Three primary areas were addressed via the interview protocol:

1. Conceptualization of CSA and risk. 
2. Child CSA education as prevention.

3. Parenting and protection.

These topics of interest were captured with open-ended questions about: (a) sexual abuse and grooming (b) CSA prevention methods and education as prevention; (c) unintended sideeffects of education as prevention; (d) effectiveness of education as prevention; (e) parents' roles in prevention; (f) details of CSA discussions (g); prevention programs; (h) CSA risk factors and the risk for their child; and (i) parental desire for more information and/or resources. Questions were standardized across participants and presented in the same order. Follow-up questions were also included in the interview protocol, which could vary depending on participant answers to the primary questions.

\section{Definitions}

This study uses the World Health Organization (WHO, 1999, p. 15) definition of child sexual abuse: "the involvement of a child in sexual activity that he or she does not fully comprehend, is unable to give informed consent to, or for which the child is not developmentally prepared and cannot give consent, or that violates the laws or social taboos of society. Child sexual abuse is evidenced by this activity between a child and an adult or another child who by age or development is in a relationship of responsibility, trust or power, the activity being intended to gratify or satisfy the needs of the other person."

The term "child CSA education" or "child education" used throughout this paper encompasses any education or information dissemination aimed at a child about CSA and related protective behaviors, regardless of the source (i.e., parents, teachers, charities). "Parent-led education" is intended to specify that a parent or care-givers is the source of the teaching process. 


\section{Data Analysis}

The first author transcribed the audio recordings verbatim (without identifying information). Thematic analysis was applied by the authors to gain a rich and authentic description of the interview content (Braun \& Clarke, 2006). All transcripts were initially reviewed by the first author, who used an inductive, semantic approach to perform preliminary coding and theme identification, progressing from descriptive to interpretative coding (Braun \& Clarke, 2006; Saladaña, 2013). The first author then re-read each inter- view several times and manually coded line by line according to this coding structure. New codes were added, and some codes were removed, renamed or merged during this process of re-reading and coding. The codes were then assigned into overarching themes which were reviewed, compared and classified by the two authors to create a thematic map. Twenty percent of the transcripts were read and coded independently by the second author. All codes and final thematic maps were discussed. Agreement between the two authors progressed from $98 \%$ to $100 \%$ upon discussion. Finally, representative quotes were extracted from the interviews to highlight the interview content that gave rise to the thematic map.

\section{Results}

\section{Theme 1: Parents' Understanding of CSA, Grooming and Risk}

Defining CSA. When compared to the WHO (1999, p. 15) definition, all parents were able to give an adequate definition of CSA. All parents described CSA as sexual contact between a child and an adult or older person in the first instance. When probed for more details, parents mentioned that CSA could include verbal, emotional, or physical actions or behaviors, and often involves manipulation, control, and unequal power relations. Parents also elaborated on the extent of the age-and/or-development-gap required in order for the actions to be defined as 
"abuse." Moreover, 19 parents (79\%) were aware of the concept of grooming in relation to CSA and gave detailed definitions, mentioning: (a) the gaining of trust ( $n=12,63 \%)$; (b) desensitization/normalization of sexual activities $(n=7,37 \%)$; (c) development of relationship/friendship/emotional connection ( $n=11,58 \%)$; and (d) gift giving $(n=5,26 \%)$. Five parents (26\%) had not heard of the term "grooming" in relation to CSA.

When asked to define CSA, most parents $(n=15,63 \%)$ went further than the WHO definition to include all peer sexual interaction, regardless of differences in power, age and development. For example: "I would think even with kids...with each other...showing themselves... [that is abuse]" (P05), "It's inappropriate behavior. And I would be really devastated if that [peer sexual interaction] happened to my child" (P19). Alternatively, 6 parents (25\%) thought that some sexual contact between children of the same age constituted experimentation and learning rather than abuse: “...kids doing stuff like you show me yours...it's all about finding their sexuality.... So, till about 16 I find that experimental and I don't think that's inappropriate" (P21).

Understanding perpetrators and CSA dynamics. Parents were aware that CSA usually occurs within children's close social networks, with 7 (29\%) mentioning it spontaneously: "we know that it is far more from people within their circle" (P14), "9 times out of 10 the perpetrator is someone that knows them, a friend of the family or a relative" (P09). Despite this knowledge, the majority of parents $(n=20,83 \%)$ seemed to concentrate on CSA as abduction or 'stranger danger' when talking about the risks and warnings given in their own children's lives. For example: The risk "is quite low [...] they are never alone with strangers" (P04), "I get to know all the teachers and um, I like to think that I am a good judge of character..." (P15), "the school is pretty good...[with CSA prevention]... they have done two drills this year regarding strangers 
[...] where [the kids] have to stay under their desks" (P17), "I've taught them what to do if they are grabbed" (P11). "if a stranger touches you there you need to tell me" (P18), children need to know about the "things that strangers will do and things that can happen" (P18), discussing CSA with children is "usually in context. So, if we are out and about and there is an opportunity for abduction or anything like that, she'll [wife] take the opportunity to explain those sorts of things" (P22), "Like, if someone tries to take you...these are the things you should do.... scream, attack, whatever" (P05).

Some parents recognized the complex interpersonal dynamics of sexual abuse, with fourteen parents (58\%) acknowledging a child may be acquiescent in the abuse; using words such as "wanted," acknowledging that the attention and affection received during the abuse may have been reinforcing for the child, and referring to the possibility of the child having a "crush" on an adult. For example: 'I'm not even going to say 'unwanted', because it's not necessarily "unwanted"” (P04), "they might hold a bit of shame, because they may have partly enjoyed it" (P21), "they interpret it as love or a crush or whatever" (P16). Alternatively, some parents felt that sexual abuse involves unwanted gestures inflicted on an unconsenting child "I guess it is someone that is not consenting to sexual gestures or behaviors" (P22), "Anything that is done against the will of the child" (P18).

CSA Risk. The majority of parents $(n=15,63 \%)$ mentioned parenting and familial risk factors first when asked, "Who do you believe is most at risk of grooming and/or sexual abuse?" Risk factors mentioned by parents were: (a) parental absence/child alone/other carers $(n=9$, $60 \%$ ); (b) lack of supervision/monitoring ( $n=7,47 \%)$; (c) lack of attention/love ( $n=6,40 \%)$; (d) parental separation/blended families $(n=5,33 \%)$; and (e) neglect/maltreatment $(n=5,33 \%)$. Also mentioned were relationship with parents, alcohol/drugs misuse, and physical or mental illness. 
Four parents (17\%) mentioned child personality factors first (e.g. shy children) and five (21\%) mentioned a child's lack of knowledge.

When asked about their own children's risk of CSA, 21 parents $(86 \%)$ said their children were at very low, low, or fairly low risk. One parent said low to moderate risk and one said average risk. This parent appraised her children to be of average risk due to both the presence of a stepfather in the house and the lower level of supervision her children receive under their birthfather's care. No scale with which to measure risk was provided to parents, with these rating categories used spontaneously by participants.

\section{Theme 2: Parent-Led CSA Education}

When asked about possible prevention methods, most parents $(n=18,75 \%)$ mentioned child-education first. Half of parents $(n=12,50 \%)$ said that child education would be their top intervention of choice, or believed that it was the most effective method of prevention. However, none reported personally giving their children comprehensive CSA prevention messages as recommended by organizations such as 'Stop it Now' (n.d.) and 'Darkness to Light' (n.d.). Such organizations recommend that children are told often, and from a young age, about CSA, using concrete examples and reinforcing that perpetrators can be trusted others, family members and teenagers, with a description of the incentives offenders may use.

Of the 12 parents who thought child knowledge was the best way to protect children, a small minority met one or more of the recommended guidelines. Two parents $(17 \%)$ began discussing CSA specifics (i.e. that someone might touch the child's genitals or ask the child to touch their genitals) early (age 4 or younger). Two (17\%) participants told their children that the perpetrator might be a family member, and three (25\%) said it might be a known person, however none said it could be a teenager. None of the parents reported mentioning the incentives 
perpetrators may use (in the context of CSA rather than abduction). Three (25\%) talked about specific behaviors and/or gave their children specific examples (e.g., someone might touch the child's genitals, someone might ask the child to touch their genitals, someone might ask the child to shower with them). Even parents who felt most strongly that knowledge was the key to protection, did not give their children comprehensive information about CSA. This perspective is illustrated by a quote from P12 when describing how she talked to her 7-year-old daughter:

I've not been specific. I've not kind of said, you know about sexual acts or anything like that. I've just talked about being comfortable and not being pushed into something you don't want to do. Basically, I've not gone into great detail.

And P19, who raised the topic on a single occasion when her daughter was 8-years-old by telling her about the parts of the body and asking: "has anyone ever done anything that you weren't happy with and she said no. And I said, well, if anyone ever does you need to tell a teacher or me or dad or an adult that you trust." P19 admitted she was "probably a bit vague.

\section{Theme 3: Parents' Beliefs about CSA Education}

Doubts about effectiveness and concerns about harm. The majority of parents had doubts about the effectiveness of child-education, and concerns about possible harms or negative side-effects. Out of all 24 participants, 14 (58\%) parents expressed considerable skepticism that child-education would help their children avoid CSA. Most parents $(n=20,83 \%)$ also expressed concerns that telling their children about specific abusive behaviors, and the identity of perpetrators, might have negative side-effects. The most common concerns were the potential side-effects of fear/anxiety ( $n=11,46 \%)$, loss of trust $(n=9,36 \%)$, damage to relationships ( $n=6$, $25 \%)$, and loss of innocence $(n=3,13 \%)$. Parents also mentioned hypervigilance, negative body image, nightmares, upset, and curiosity about sex. For example, two parents expressed concerns 
about the effectiveness of CSA education in the following ways: "let's face it...I don't think you can stop it from happening. Obviously, the adult is in the wrong and they are going to do everything in their power to keep it a secret" (P11), "No, there is no way a child can prevent abuse. Recognize it. Stop it. Say no to someone..." (P16).

Ten (42\%) parents said they believed CSA education would help their child resist or avoid abuse. However, four parents of these parents still expressed some doubt: "I hope so. I don't know if it's enough...But hopefully it will..." (P06), "Yeah...I think it might" (P15), "Yeah, well, depending on their age and maturity" (P13). Seven (29\%) parents thought educating children might help children more with disclosure rather than prevention.

Parent participation in CSA education. Although no participants met all the guidelines for talking with children about CSA recommended by 'Stop it Now' (n.d.) and 'Darkness to Light' (n.d.), five (21\%) came close by describing how they had told their children about specific behaviors (e.g. someone might try and touch your private parts or show you their private parts), and that the perpetrator could be a family member, or someone known to them. Of these five parents, two had some doubts about how effective child-education would be and three thought there may be harms associated with it. Only 1 out of the 5 participants thought child education had no harms and/or did not doubt its effectiveness. For example, one parent expressed doubts about whether the method would work:

it depends how good that person's psychological hold over the kid is. How well-groomed they are. [...] So, knowledge will not stop all cases, because sometimes the child might want it... [...] ... And knowing might not actually prevent it... coz its more about protecting that child .... I mean, they are just children, so they can't be responsible for that sort of thing, at that age. So, knowing about it, might even just make them more 
paranoid and even a bit more withdrawn from adults and might even prevent some good relationships with adults. (P07)

The parent went on to say:

It is an awful thing for them [her children] to have to think about... [...] ...it takes away their innocence. I don't like that part of it.... but at the same time, if you want your children to be a little bit armed against this kinda stuff you have to...which is sad. I just find the whole thing sad... that we even have to go there with our kids. But in the long run the benefits outweigh the risk. (P07)

One parent thought that a side effect of his detailed CSA discussions with his children might be that they, like him, become too suspicious of people, leading to social implications: And I don't want them to miss out on anything in life. Because, especially if it's to do with love or affection or someone caring for them. Yeah, I guess they will reappraise some relationships after what I said, but again, if that's the downside [...] missing out on a little bit of affection or losing trust in people.... if that's the downside, I would still keep doing what I do. (P21)

\section{Theme 4: Children Recognizing and Resisting CSA}

Although the parents in this study varied in the degree to which they felt that children would be able to protect themselves, almost all parents made comments that suggested children have to recognize and resist CSA by making decisions and enacting certain behaviors in social interactions to avoid or prevent an abusive encounter occurring. Some also acknowledged that this could be difficult for children. More specifically, 21 parents $(86 \%)$ mentioned child responsibility in some way:

We need to educate our children and advise them that is this happens, even if it's with 
someone you know, even if it's your parent, sibling, cousin-No, it's your body and this is what you need to do to protect yourself. (P24)

P24 tells his 5-year-old son “...you go to ... someone responsible and you don't let that happen. You prevent that before it happens..." This father also said that when his children begin to receive 'sleep-over' invitations he will ask them:

What is their plan to prevent this kind of behavior? [...] 'what are you going to do.... tell me.' And if they fail, maybe I wouldn't let them have sleep-overs until I feel they are ready and they know exactly how to deal with a scenario like that. (P24)

This same dad was quite straightforward about his 5-year-old child's responsibility: Then, at least, he'll know that he could, sort of, prevent it from happening. If he sees that coming into action, and someone is making a move, then he knows how to stop it. [...] I constantly remind him that he has to resist, that he has to say no. (P24)

P06's children (aged 5 and 7) should be able to "know and recognize and try not to find themselves in possible situations... [...] to see from afar what could possibly happen..." and "[the child] needs to make sure that these things don't happen." P06 is trying to teach her young sons how to discriminate between scenarios. "so, if a friend of mine is helping you to put your togs $\{$ swimmers $\}$ on, you should just see that as someone helping you to put your togs on."

Further illustrating the theme of perceived child responsibility, some parents told their young children (aged 3-8) to be vigilant to dangers, including not to be alone with people, “...don't put yourself in that situation where you are alone with someone” (P13). P03 said "We've told them that there are risks everywhere around them that they need to be vigilant about and know how to be safe."

In acknowledging that actions might be difficult for children, these quotes illustrate how 
Parents and CSA Prevention 20

parents described the challenges:

Abuse is usually about manipulation and control and children don't understand that.

That really can't be taught. People don't realize that until they are fully grown adults.

And even adults can be manipulated. Educating the child alone is of limited use. (P03)

So, I think definitely children are not able to prevent grooming because they can't

recognize it at all... if children could recognize grooming then that would be worrying, I

think, because basically grooming is someone being really nice to them and wanting to be around them and talking to them and listening to them [...] and so to think that children can identify it would be a problem because then that child basically wouldn't trust anyone. (P16)

\section{Theme 5: Parent responsibility for Protection}

One half of parents $(n=12,50 \%)$ said good parenting practices would be their top intervention of choice or thought it was the most effective method of prevention. Parents were also asked 'What are the things that parents can do to keep children safe?' In response, 10 parents (42\%) mentioned actual parenting behaviors (such as supervision and involvement). Six (25\%) participants felt that parents keep children safe through the dissemination of CSA

knowledge only (i.e., parents educating their children about CSA). While the remaining 8 parents $(33 \%)$ felt that parents kept children safe through a combination of positive parenting practices and parent-led CSA education of their children. Two parents that ranked child knowledge as the most effective technique found it difficult to see how any other aspects of parenting, other than parent-led education, could be protective.

When comments throughout the interview were considered, the most often mentioned protective parenting strategies and characteristics were: supervision/monitoring $(n=22,92 \%)$, 
involvement/ engagement $(n=15,63 \%)$, open communication $(n=13,54 \%)$, decisions about contact/care by others $(n=11,46 \%)$, "being there" $(n=10,42 \%)$, parent-child relationship $(n=10$, $46 \%)$, love $(n=6,25 \%)$, and vigilance $(n=4,17 \%)$. The following quotes illustrate how parents expressed their own or other parents' roles in protection:

Parents parenting. Parenting their kids. If you have a kid, you parent it. And there's a level of parenting that you need to adhere to. And vigilance is at the top. Being involved in your child's life, taking an interest. (P18)

"I think what can help the child is all the things I've mentioned about keeping them safe and they should never to responsible for stopping the abuse. It should be the adults involved" (P16). "For me, it comes back to parents being vigilant. Being aware. Being active. Being involved in their kids' lives. That's the only way [...] that anything can be done" (P07), "Good parenting would stop it earlier than the child saying 'no' could" (P03), "I think probably 99\% of it lies with the adult providing a safe environment and being protective and vigilant. I feel like the adult is the one more armed to do that, more than the child would ever be" (P03), "The rest is up to me and [my wife] to make sure their environment is as safe as is reasonably possible. But it's not their responsibility. It's my responsibility to look out for them... as much as I can” (P01). Parental desire for CSA prevention information. In response to the question "Do you sometimes wish or think you could use some ideas, resources or information on how to better protect your children from sexual abuse?" 12 (50\%) parents said yes: "I would like guidance on it” (PAR09), “Oh God, yeah. I think it's really hard to keep up” (P12), “Absolutely. I'm new to all this" (P20). Ten (42\%) parents said no: "No, I think I'm ok in that department. You just have to go and look up things" (P06), "I think I have enough! So much information!” (P13), "I think I'm ok, but I think in general it could be good for parents, definitely" (P14). Two parents were 
not sure if more information would be helpful.

\section{Discussion}

The aims of this qualitative study of 24 Australian parents were to 1) detail parents' definitions of CSA and their views on CSA prevention; 2) approach prevention research with parents as the key agents in prevention; 3) probe parent prevention strategies other than parentled education; 4) identify parental attitudes towards child education as a prevention method, and 5) inform future prevention research with parents. Overall, the findings demonstrated that parents had a good understanding of CSA, grooming and risk, yet varied greatly in the frequency and detail of CSA education they provided to their children. None described giving their children the information that would meet recommended guidelines. This may be due to most of the sample assessing their children as low risk, many parents having doubts about the effectiveness of education in protecting their children and most parents having concerns about possible negative side effects from CSA education. Regarding responsibility for prevention, a large proportion of parents made statements suggesting child responsibility in prevention (e.g., a child can recognize and stop grooming and abuse). Half of parents endorsed good parenting practices as the best prevention method. How the findings extend knowledge on parenting and prevention in novel ways, and the implications of the findings for the involvement of parents in CSA prevention, is discussed below.

\section{Parents' Understanding of CSA, Grooming, and Risk}

In accord with previous research (Finkelhor, 1984; Hébert et al., 2002; Reppucci et al., 1994; Tutty, 1993), parents in this study had a good understanding of CSA and perpetrators' grooming behaviors. Consistent with this knowledge, only half of study parents felt they would like more resources or information, which diverges from previous research which has described 
parents desiring more information (e.g., Wurtele, Moreno \& Kenny, 2008). Although additional research with larger samples is needed, the high level of knowledge demonstrated by the parents in this study, and the large number of parents who did not want more information, suggests that the design of parenting programs/campaigns could be improved based on a better understanding of what parents want (or feel they need) to know. It may be that parents require more specific information about offender behavior such as targeting and isolation of victims, and parenting behaviors to mitigate this such as supervision, rather than routine facts about CSA.

Although the WHO includes abuse by other children in its CSA definition, it specifies there to be an inequality of age, development and power (WHO, 1999). In keeping with contemporary norms (Flanagan; 2011; Wurtele \& Kenny, 2011), the majority of parents in this study deemed all child-child sexual interaction to be abusive. According to Flanagan any association of "child" and "sexual" is generally seen as problematic: "In response to the awareness of child abuse, one position remains dominant: that any "sexualized" language or action in children is seen as a possible sign of abuse. A question of "deviancy" is almost automatic in the context of children and sexual activity" (2011, p.74). Despite this, there is evidence to suggest that childhood sexual attraction and "sexual play" is commonplace and not usually maladaptive (Flanagan, 2011; Herdt \& McClintock, 2000; Wurtele \& Kenny, 2011): "middle childhood is a time in which general psychophysiological arousal, including erotic feelings and events previously unknown or unrecognized, produces increasingly memorable and stable sexual attraction" (Herdt \& McClintock, 2000, p. 588). Given the proportion of parents who thought sexual interaction of children with their peers was problematic, it may be helpful to include information about normative childhood sexual behavior in any CSA education program for parents. This may assist them with the identification of genuine problematic sexual behavior 
as well as their response to any discovery of peer sexual contact involving their children.

The current study findings support previous research that, despite their knowledge to the contrary, when it came to describing situations with their own children, evaluating risk and giving warnings, parents routinely referred to child abduction; focusing on strangers and external environments rather than established relationships and domestic surroundings (Deblings et al., 2012; Walsh \& Brandon, 2012). Drawing from the notion of cognitive biases, parents may act contrary to their knowledge due to the illusory correlation. Misrepresentations, especially in the media, of CSA as abduction, causes these rare and novel occurrences to become more salient, leading to false associations of CSA as abduction (Chapman, 1967). Alternatively, cognitive dissonance theory suggests that the mental discomfort which arises from believing one's friends or family members could perpetrate sexual abuse, precludes actions or thoughts which confirm this belief, leading parents to conceptualize CSA as abduction when it comes to their own children (Festinger, 1957). Other explanations are possible. For example, parental self-protection may result in parents' avoidance of the "aversive" task of addressing this difficult topic with their children; or skill deficits may leave parents unable to talk to their children about sexual subjects. Further research is required; however, it seems that parents find it very difficult to map their knowledge of CSA risk onto their own child's circumstances. This adds evidence to other research suggesting that increasing parents' CSA knowledge in order to encourage them to give their children comprehensive prevention messages, may be ineffective (Rudolph et al., 2018b). Parent education may require a hands-on component, in which parents explore their children's current interactions with close others and consciously map CSA risk, rather than abduction risk, on to these (e.g., through the use of a risk checklist across situations and settings).

The majority of parents in this study described how children may acquiesce to the 
abusive situation (Berliner \& Conte, 1990; Rind, Tromovitch \& Bauserman, 1998). This finding suggests that parents have insight into the nuances of CSA, which may aid them to respond with support to disclosures of sexual abuse, if ever required. This finding also suggests that parent education initiatives should include information about children's experience of abuse, possibly in the form of victim statements such as described in Berliner and Conte (1990), to enhance and reinforce parents' understanding of these complexities.

When asked about the circumstances that make children more vulnerable to CSA, the majority of parents mentioned evidence-based risk factors such as negligent or uninvolved parenting practices (Black, Heyman, \& Smith Slep, 2001). Only five parents mentioned a lack of knowledge about CSA. When asked to consider their own children's risks, almost all parents thought their children were at low risk, concurring with previous research (Collins, 1996; Elrod \& Rubin, 1993; Finkelhor, 1984; Reppucci et al., 1994; Rudolph et al., 2018b; Tutty, 1993; Xie et al., 2015). The appraisal of highest risk was 'average' denoted by a parent who felt her children are not properly supervised when they are cared for by their father and because she has a new partner. Parental appraisal of their children's risk does not seem to be associated with willingness to educate about CSA (Burgess \& Wurtele, 1998; Rudolph et al., 2018b), as was confirmed in this study, with parents giving their children differing amounts of CSA information regardless of the uniform appraisal of low risk.

\section{Parent-Led CSA Education}

Increasing children's knowledge about CSA has been the primary focus of prevention, given that it is expected to protect children from abuse (Kenny et al., 2008; Walsh et al., 2018). Yet, in the current study, parents were reluctant to provide comprehensive education to their children about CSA risks, as has been found previously (Rudolph et al., 2018b; Walsh et al., 
2012). In fact, in this study, no parent reported providing education consistent with recommendationed guidelines (e.g. Darkness to Light and Stop it Now). Even those parents who described education as key to prevention reported that they had not provided comprehensive education to their children. This complicates the matter of using education as prevention and suggests that changing parents' beliefs about the usefulness of education may still not result in more parent-led education about CSA.

\section{Parent Beliefs about CSA Education and Protection}

Giving more weight to the idea that parents may choose not to give their children comprehensive CSA messages, the majority of parents in this study had doubts about the effectiveness of child CSA education in actually helping their children avoid abuse. Furthermore, only a third of the parents who endorsed education as the most effective technique and/or their primary choice of prevention technique, endorsed the view that it would help a child confront abuse (although not unconditionally). Almost all parents also described potential harms, such as fear, anxiety, loss of trust and innocence and damage to relationships. Yet, some parents were able to override their concerns by giving their children specific CSA messages, despite reporting concerns about effectiveness and harms.

Sexual abuse prevention is moving towards being more explicit about the ways that adults can take greater responsibility for child protection (Darkness to Light's 5 Steps to Protecting our Children, n.d.; Mendelson \& Letourneau, 2015; Wurtele, 2010). In the present study, parents endorsed specific parenting techniques as more effective than parent dissemination of knowledge to their children. In addition, good parenting skills were described as the top prevention of choice/most effective method by half of the parents.

These findings further illuminate some potential reasons the CSA prevention field has 
encountered resistance when attempting to encourage parents to educate their children. Future research on this topic is needed, as these findings could reveal ways to develop more effective CSA prevention programs involving parents. For example, it may be that parental involvement in prevention may be better harnessed through assisting parents in positive parenting skills and the creation of safe environments. Parents in this study were aware of what aspects of parenting strategies could be important in CSA prevention (e.g., Black et al., 2001), suggesting that parents may be receptive to more information about how to tailor parenting to further enhance protection.

\section{Children Recognizing and Resisting CSA, and Parent Responsibility}

Partly in response to critics equating child education with child responsibility, the CSA prevention field has increasingly taken care to avoid the suggestion that children are responsible for preventing their own sexual victimization (Babatsikos \& Miles, 2015; Kenny et al., 2008). Further, evidence for limiting the responsibility placed on children for their protection comes from the children themselves: from research on the low rates of disclosure (London, Bruck, Wright, \& Ceci, 2008), the reasons for non-disclosure (McElvaney, 2015), the victim experience of abuse (Berliner \& Conte, 1990) and the shame/guilt that victims experience (Perilloux, Duntley, \& Buss, 2014); and from offenders conveying information about their modus operandi (Leclerc, Beauregard, \& Proulx, 2008).

Although most of the parents in this study did not directly state during interviews that their children were responsible for preventing their own abuse, analysis of the interviews suggests that many parents do have high expectations that their children will avoid or escape abusive scenarios. Parents expected their children to appraise social situations, be on guard for signs of danger and make decisions accordingly. For example, parents wanted their young 
children to be able to distinguish between someone helping them (e.g. assisting with dressing, or medically) and CSA grooming. As evidence suggests grooming occurs in exactly these circumstances (Leclerc et al., 2008), it may be very difficult, or perhaps impossible, for a young child to clearly understand the difference. Parents also wanted their children to avoid being alone with people, which might involve social engineering beyond the capacity of young children.

It is difficult to know what effect these expectations have on children in terms of generalized anxiety, hypervigilance and sense of trust. Nishikawa and Stolle (2012) theorized that the sense of imposing danger planted by parents is partly driving the decrease in social trust that has been documented over the last 40 years. It is also possible that subtle messages of responsibility could result in children's feeling of shame and guilt if CSA does occur. Given these possibilities, it may be prudent to include information on victim experiences of abuse and disclosure, and the developmental capacities of children to interpret and influence social situations in education programs for parents, in order for parents to have realistic expectations of the extent that children can understand and confront grooming and abuse.

\section{Study Limitations and Conclusion}

The generalizability of these results must be considered within the limits of the small sample size. Although the sample included culturally diverse participants, they were recruited from two sites within one urban geographical area of Australia. The socio-economic status of the participants was higher than that of the general Australian population; approximately $70 \%$ of the sample reported earnings above the average wage. It is important to replicate this study with parents from a greater diversity of social-economic strata, and from varied locations, such as those parents living in rural/remote areas. Father's voices are generally not heard in CSA research and, although the present sample was $29 \%$ male, it fell short of being representative of 
the population. Future research should attempt to actively recruit more fathers. Many people find sexual abuse a difficult subject to discuss, and these results must be considered within the limits of socially desirable reporting.

\section{Conclusion}

The findings of the present study revealed that parents have a solid understanding of CSA and perpetrators' grooming behaviors, but tend to consider abduction, rather than the risk of CSA by close others, when contemplating their own children's risk of CSA. None of the parents gave their children complete and comprehension CSA messages, despite half of parents believing education to be the best method of prevention. This may be due to large numbers of parents feeling that education may have unintended negative side-effects and may not be effective in helping their children in an abusive encounter. In 30 years of research, findings have repeatedly indicated that parents demonstrate some reluctance in providing comprehensive CSA information to their children (Deblinger et al., 2012; Finkelhor, 1984; Rudolph et al., 2018b; Walsh et al., 2012; Wurtele et al., 1992). As expressed by many parents in this study, the most significant parental contribution to protection against CSA is their capacity to create safer environments for their children and nurture their positive well-being. In view of this, we recommend that more resources (financial, human and intellectual) be devoted to the design, creation, implementation, and evaluation of parenting-targeted interventions - shifting the focus from parents as educators, to parents as protectors.

\section{References}

Babatsikos, G. (2011). Australian parents, child sexuality, and boundary setting: informing preventative approaches to child sexual abuse. (Unpublished doctoral dissertation). James Cook University, Townsville, Australia. 
Parents and CSA Prevention 30

Babatsikos, G, \& Miles, D. (2015). How parents manage the risk of child sexual abuse: A grounded theory. Journal of Child Sexual Abuse, 24, 55. doi:10.1080/10538712.2015.981352

Berliner, L., \& Conte, J. R. (1990). The process of victimization: The victims' perspective. Child Abuse \& Neglect, 14(1), 29-40. doi:10.1016/0145-2134(90)90078-8

Black, D. A., Heyman, R. E., \& Smith Slep, A. M. (2001). Risk factors for child sexual abuse. Aggression and Violent Behavior, 6, 203-229. doi:10.1016/S1359-1789(00)00023-9

Braun, V., \& Clarke, V. (2006). Using thematic analysis in psychology. Qualitative research in psychology, 3, 77-101.

Briggs. F. (1988). South Australian parents want child protection programs to be offered in schools and preschools. Early Child Development and Care, 34, 167-178. doi:10.1080/0300443880340112

Burgess, E. S., \& Wurtele, S. K. (1998). Enhancing parent-child communication about sexual abuse: A pilot study. Child Abuse \& Neglect, 22, 1167-1175. doi:10.1016/S01452134(98)00094-5

Chapman, L. (1967). Illusory correlation in observational report. Journal of Verbal Learning and Verbal Behavior. 6151-155. doi:10.1016/S0022-5371(67)80066-5

Chen, J. Q., \& Chen, D. G. (2005). Awareness of child sexual abuse prevention education among parents of grade 3 elementary school pupils in Fuxin City, China. Health Education Research, 20, 540-547. doi:10.1093/her/cyh012

Chen, J., Dunne, M. P., \& Han, P. (2007). Prevention of child sexual abuse in China: Knowledge, attitudes, and communication practices of parents of elementary school children. Child Abuse \& Neglect, 31, 747-755. doi:10.1016/j.chiabu.2006.12.013 
Parents and CSA Prevention 31

Collins, M. (1996). Parents' perceptions of the risk of child sexual abuse and their protective behaviors: Findings from a qualitative study. Child Maltreatment, 1, 53-64. doi:10.1177/1077559596001001006

Darkness to Light. (n.d.). Step 3: Talk about it. Retrieved from https://www.d21.org/education/5steps/step-3/

Deblinger, E., Thakkar-Kolar, R. R., Berry, E. J., \& Schroeder, C. M. (2010). Caregivers' efforts to educate their children about child sexual abuse: A replication study. Child Maltreatment, 15, 91-100. doi:10.1177/1077559509337408

Elrod, J. M., \& Rubin, R. H. (1993). Parental involvement in sexual abuse prevention education. Child Abuse \& Neglect, 17, 527-538. doi:10.1016/0145-2134(93)90027-3

Festinger, L. (1957). A Theory of Cognitive Dissonance. California: Stanford University Press. Finkelhor, D. (1984). Child sexual abuse: New theory and research. New York: Free Press. Finkelhor, D., Asdigian, N., \& Dziuba-Leatherman, J. (1995). The effectiveness of victimization prevention instruction: An evaluation of children's responses to actual threats and assaults. Child Abuse \& Neglect, 19, 141-153. doi:10.1016/0145-2134(94)00112-8

Finkelhor, D., Vanderminden, J., Turner, H., Shattuck, A., \& Hamby, S. (2014). Youth exposure to violence prevention programs in a national sample. Child Abuse \& Neglect, 38, 677686. doi:10.1016/j.chiabu.2014.01.010

Flanagan, P. (2011). Making sense of children's sexuality: Understanding sexual development and activity in education contexts. Waikato Journal of Education, 16, 69-79.

Foster, J. M. (2017). Engaging Parents and Caregivers in the Prevention of Child Sexual Abuse. Journal of Trauma \& Treatment, 6. doi:10.4172/2167-1222.1000367

Hébert, M., Lavoie, F., \& Parent, N. (2002). An assessment of outcomes following parents' 
Parents and CSA Prevention 32

participation in a child abuse prevention program. Violence and Victims, 17, 355-372. doi:10.1891/vivi.17.3.355.33664

Herdt, G., \& McClintock, M. (2000). The magical age of 10. Archives of Sexual Behavior, 29, 587-606. doi:10.1023/A:1002006521067

Ige, O. K., \& Fawole, O. I. (2011). Preventing child sexual abuse: Parents' perceptions and practices in urban Nigeria. Journal of Child Sexual Abuse, 20, 695-707. doi:10.1080/10538712.2011.627584

Kenny, M. C., Capri, V., R, R., Thakkar-Kolar, R. R., Ryan, E. E., \& Runyon, M. K. (2008). Child sexual abuse: From prevention to self-protection. Child Abuse Review, 17, 36-54. doi:10.1002/car.1012

Ko, S. F., \& Cosden, M. A. (2001). Do elementary school-based child abuse prevention programs work? A high school follow-up. Psychology in the Schools, 38, 57-66. doi:10.1002/1520-6807(200101)38:1<57::AID-PITS6>3.0.CO;2-W

Leclerc, B., Beauregard, E., \& Proulx, J. (2008). Modus operandi and situational aspects in adolescent sexual offenses against children: A further examination. International Journal of Offender Therapy and Comparative Criminology, 52, 46-61. doi:10.1177/0306624X07300271

London, K., Bruck, M., Wright, D., \& Ceci, S. (2008). Review of the contemporary literature on how children report sexual abuse to others: Findings, methodological issues, and implications for forensic interviewers. Memory, 16, 29-47. doi:10.1080/09658210701725732

Mian, M., \& Collin-Vézina, D. (2017). Adopting a public health approach to addressing child sexual abuse and exploitation. Child Abuse \& Neglect, 66, 152-154. 
https://doi.org/10.1016/j.chiabu.2017.02.035.

Mathoma, A. M., Maripe-Perera, D. B., Khumalo, L. P., Mbayi, B. L., \& Seloilwe, E. S. (2006). Knowledge and perceptions of parents regarding child sexual abuse in Botswana and Swaziland. Journal of Pediatric Nursing, 21, 67-72. doi:10.1016/j.pedn.2005.08.002

McElvaney, R. (2015). Disclosure of child sexual abuse: Delays, non-disclosure and partial disclosure. What the research tells us and implications for practice. Child Abuse Review, 24, 159-169. doi: 10.1002/car.2280

Mendelson, T., \& Letourneau, E. J. (2015). Parent-focused prevention of child sexual abuse. Prevention Science, 16, 844-852. doi:10.1007/s11121-015-0553-z

Nishikawa, L., \& Stolle, D. (2012). Do not trust strangers-How parents shape the generalized trust of their children. In M. Sasaki \& R. M. Marsh (Eds.), Trust: Comparative perspectives (1st ed., pp. 133-171). Boston, MA: Brill.

Pelcovitz, D., Adler, N. A., Kaplan, S., Packman, L., \& Krieger, R. (1992). The failure of a school-based child sexual abuse prevention program. Journal of the American Academy of Child \& Adolescent Psychiatry, 31, 887-892. Retrieved from https://sites.google.com/site/dpelcovitz/publications

Perilloux, C., Duntley, J. D., \& Buss, D. M. (2014). Blame attribution in sexual victimization. Personality and individual differences, 63, 81-86. doi.org/10.1016/j.paid.2014.01.058 Reppucci, N. D., Jones, L. M., \& Cook, S. L. (1994). Involving parents in child sexual abuse prevention programs. Journal of Child and Family Studies, 3, 137-142.

Rind, B., Tromovitch, P., \& Bauserman, R. (1998). A meta-analytic examination of assumed properties of child sexual abuse using college samples. Psychological Bulletin, 124, 2253. doi:10.1037/0033-2909.124.1.22 
Rogers, R. W. (1983). Cognitive and physiological processes in fear appeals and attitude change: A revised theory of protection motivation. In J. T. Cacioppo \& R. E. Petty (Eds.), Social Psychophysiology: A Sourcebook (pp. 153-176). New York: Guilford Press.

Rudolph, J., Zimmer-Gembeck, M. J., Shanley, D., \& Hawkins, R. (2018a). Child sexual abuse prevention opportunities: Parenting, programs and the reduction of risk. Child Maltreatment. doi:10.1177/1077559517729479

Rudolph, J., Zimmer-Gembeck, M. J., Shanley, D., Walsh., K., \& Hawkins, R. (2018b). Parenting practices and child sexual abuse risk: Are warm and involved parents more likely to discuss risk and protection with their children? Journal of Child Sexual Abuse. doi.org/10.1080/10538712.2018.1425946

Saladaña, J. (2013). The coding manual for qualitative researchers (2nd ed.). Thousand Oaks, CA, USA: Sage.

Stop it Now. (n.d.). Tip sheet: Talking to children and teens. Retrieved from http://www.stopitnow.org/ohc-content/tip-sheet-8

Tutty, L. (1993). The relationship of parental knowledge and children's learning of child sexual abuse prevention concepts. Journal of Child Sexual Abuse, 2, 83-103. doi:10.1300/J070v02n01_06

Walsh, K., \& Brandon, L. (2012). Their children's first educators: Parents' views about child sexual abuse prevention education. Journal of Child and Family Studies, 21, 734-746. doi:10.1007/s10826-011-9526-4

Walsh, K., Brandon, L., \& Chirio, L. (2012). Mother-child communication about sexual abuse prevention. Journal of Child Sexual Abuse, 21, 399-421. doi:10.1080/10538712.2012.675424 
Walsh, K., Zwi, K., Woolfenden, S., \& Shlonsky, A. (2018). School-based education programs for the prevention of child sexual abuse: A cochrane systematic review and metaanalysis. Research on Social Work Practice, 28, 33-55. doi:10.1177/1049731515619705

World Health Organization (1999). Report of the Consultation on Child Abuse Prevention. Geneva: World Health Organization.

Wurtele, S. K. (2010). Partnering with parents to prevent childhood sexual abuse. Child Abuse Review, 19, 130-152. doi:10.1002/car.1112

Wurtele, S. K., \& Kenny, M. C. (2011). Normative sexuality development in childhood: Implications for developmental guidance and prevention of childhood sexual abuse. Counseling and Human Development, 43, 1-24.

Wurtele, S. K., Kvaternick, M., \& Franklin, C. F. (1992). Sexual abuse prevention for preschoolers: A survey of parents' behaviors, attitudes, and beliefs. Journal of Child Sexual Abuse, 1, 113-128. doi:10.1300/J070v01n01_08

Wurtele S, Moreno T, Kenny M. (2008). Evaluation of a sexual abuse prevention workshop for parents of young children. Journal of Child and Adolescent Trauma, 1, 331-340. doi:10.1080/19361520802505768

Xie, Q. W., Qiao, D. P., \& Wang, X. L. (2015). Parent-Involved Prevention of Child Sexual Abuse: A Qualitative Exploration of Parents' Perceptions and Practices in Beijing. Journal of Child and Family Studies, 25, 999-1010. doi:10.1007/s10826-015-0277-5 